\title{
Investigation on the Surface Roughness When Cutting Hard Material with Plasma Arc Cutting
}

\author{
Omar Monir Koura ${ }^{1,}$, , Sarah Atef Afifi ${ }^{1}$, Mervat Tawfik ${ }^{2}$, Samah Samir Mohammed ${ }^{2}$ \\ ${ }^{1}$ Mechanical Department, Faculty of Engineering, Modern University for Technology and Information, Cairo, Egypt \\ ${ }^{2}$ Mechanical Department, Faculty of Engineering at Shobra, Benha University, Cairo, Egypt
}

Email address:

Koura_omar@yahoo.com (O. M. Koura), Sarah.Afifii@gmail.com (S. A. Afifi), mervat_2551@live.com (M. Tawfik),

Samah.samir@feng.bu.edu.2g (S. S. Mohammed)

${ }^{*}$ Corresponding author

\section{To cite this article:}

Omar Monir Koura, Sarah Atef Afifi, Mervat Tawfik, Samah Samir Mohammed. Investigation on the Surface Roughness When Cutting Hard Material with Plasma Arc Cutting. American Journal of Mechanical and Industrial Engineering. Vol. 6, No. 2, 2021, pp. 28-33.

doi: 10.11648/j.ajmie.20210602.12

Received: June 24, 2021; Accepted: July 16, 2021; Published: July 24, 2021

\begin{abstract}
Surface quality represented in the primary surface texture is the main parameter when dealing with surfaces in relative rotary and sliding motions. In conventional machining processes, if further quality in surface roughness is required, finishing and superfinishing machining operations are available. In case of extremely high resistive, hard and high strength materials conventional machining are highly uneconomical. The solution was found in cutting such hard materials is by using non-traditional processes. Plasma arc cutting was one solution. However, the surface quality as a response of the parameters involved in this process, namely gas pressure, cutting speed and standoff distance is not in the high finished quality. The aim of this paper is studying the effect of the cutting conditions of plasma arc cutting on the primary surface texture as assessed by the International standard Arithmetical Mean Average " $\mathrm{R}_{\mathrm{a}}$ " for the produced parts. Experimental work was carried out on specimen made of Hardox 400. The effect of the three considered parameters of plasma arc cutting were studied on the responded surface roughness. Results were analyzed using Minitab17 and binomial regression equations were deduced. Cutting speed showed greater effect on surface roughness and all has showed that surface roughness ranged from 5 to $5.5 \mu \mathrm{m}$.
\end{abstract}

Keywords: Plasma Arc Cutting, Primary Surface Texture, Hardox400, Minitab 17

\section{Introduction}

Abrasion-resistant (Wear-resistant) steel plates are widely used, now, in many industrial applications. They provide considerable life time for components subjected to high loads and light weights. Manufacturing such material on conventional machines is uneconomical by all means because of the sever and rapid wear in the cutting tools. The solution is to use non-conventional techniques in cutting such hard materials. Plasma arc cutting is used as one alternative. However, the produced products suffer mainly from low quality surface finish.

Milan Kumar Das et al [1] studied the effect of cutting current, gas pressure and standoff distance when cutting EN 31 steel on the quality of the produced surface roughness. The output resulted parameters represented in the material removal rate and surface roughness of machined surface were measured. They concluded that Gas pressure has a greater effect on the quality.

K. Saloitis et al [2] carried out experimental work using CNC plasma system. They used specimen made of $15 \mathrm{~mm}$ thickness S235 mild steel sheets. Oxygen gas is used as plasma (primary) gas and air is used as shielding (secondary) gas. The investigation involved changing the cutting speed, the cutting current, the cutting height and the pressure of the plasma gas. The study was to determine the effect of the input parameters on the quality of surface roughness. After several tests they found that the cutting height has the strongest effect on the surface roughness of the cut. Regarding the roughness of the cutting edge, they found that cutting height has the 
greater effect on the quality than that of the cutting speed and cutting current.

Parthkumar Patel et al [3] studied the effect of cutting speed, gas pressure and torch height on surface roughness. Both theoretical methodology and experimental work were conducted. Empirical models were predicted. Teaching learning-based optimization (TLBO) algorithm has been proposed. The results were compared with genetic algorithm (GA). The former was quoted that it has better result as compare to genetic algorithm.

Yahya hisman celik [4] studied material S235JR using the CNC plasma cutting machine at different cutting speeds, cutting current, and arc voltage. They measured their effect surface roughness of the material after cut. They concluded that the quality of plasma $\mathrm{CNC}$ machine depends on the cutting current, cutting speed, arc voltage and material thickness. To obtain a better surface roughness the cutting current and the cutting voltage should be kept low and cutting speed must be high for the thin sheet.

Chirag K. Kolambe and Sambhaji V. Sagare [5], used CNC plasma cutting machine to investigate the effect of the dominant parameters in plasm cutting on the surface roughness and other responsive parameters. They applied the Taguchi method through Minitab 17 in their analysis to show its potential.

Sagar S. and K. H. Inamdar [6] presented a review paper about the recent research in plasma arc cutting and the optimization techniques used. They came out by the most affecting factors which are arc voltage, current, standoff distance, gas pressure with its flow rate and cutting speed while the response factors being kerf width, heat affected zone, the bevel angle and the surface finish.

Deepak Kumar Naik and Kalipada Maity [7] carried out detailed experimental work covering changing the nature of the gas used from Argon to nitrogen to oxygen and finally air. Also, they changed the flow rate between 8 to $16 \mathrm{~g} / \mathrm{min}$. They concluded that kerf width was similar and with narrower width when using nitrogen or air, while metal removal rate was higher with argon gas and oxygen gas due to the maximum energy released during cutting with those gases.

Deepak K Kumar Naik and Kalipada Maity [8] focused on determining the material removal rate and the kerf quality when cutting a high abrasion - resistant steel using plasma arc cutting. The input variable considered are cutting current, standoff distance, gas pressure and cutting speed. Argon was used as the cutting gas and oxygen as a shielding gas. Their main objective was to optimize the input conditions. Response Surface Methodology was used to design the experiments. Desirability function correlating the combined effect of the input parameters was introduced. Optimal values for each condition ware presented. Second ordered polynomial model was given that correlate the input parameters with the response parameters.

Naik DK, Maity K [9] studied the temperature distribution over the surface and showed its variation as the cutting speed increases.

Same authors [10] studied the effect of the arc voltage, standoff distance and cutting speed on the machinability when cutting 304L stainless steel. Two types of gases were tested. They applied Taguchi method and analysed the results with ANOVA procedure.

Same authors [11] worked on hardox400 to investigate the individual effect of the cutting parameters on the Material removal rate, surface roughness, kerf and chamfer. Argon and Oxygen were used as the gas and the shield alternatively. They came out with certain optimal values for better machinability.

Omar Monir Koura et al [12], showed through their work that the minimum kerf width was obtained at cutting speed of $700 \mathrm{~mm} / \mathrm{min}$ and gas pressure at $300 \mathrm{KPa}$ when cutting hardox 400 .

Sovan Bhowmick et al [13], studied the effect of traverse speed, gas pressure and material thickness when cutting AISI 304 stainless steel on the material removal rate and surface roughness. Air was the gas used. From the variance analysis they concluded that gas pressure has the greater effect on surface roughness while the speed and the material thickness have more effect on the material removal rate. The optimized cutting conditions were obtained when the pressure was $0.8 \mathrm{MPa}$, speed at $217 \mathrm{~mm} / \mathrm{min}$ and thickness $8 \mathrm{~mm}$.

Pothur Hema and Ramprasad Ganesan [14] followed the same route by studying the response of arc voltage, cutting speed and standoff distance on the quality of cut. They, also, changed the nozzle size and kept the material thickness at $6 \mathrm{~mm}$. They showed that the nozzle with smaller diameter produced higher material removal rate and maintained lower surface roughness. The optimal values were obtained at 136 volts, $2000 \mathrm{~mm} / \mathrm{min}$ cutting speed and standoff distance at $2 \mathrm{~mm}$.

Pulkit Kumar Agrawal et al [15] presented a comprehensive review article for the different approaches and methods used by researchers in the field of plasma arc cutting. They considered the effect of the main cutting conditions in the process and advised of exploring other materials to be cut by plasma arc cutting.

Sahil Sharma et al [16], Applied Taguchi method in optimizing the cutting parameters. Cutting parameters considered were cutting speed, current, standoff distance and plasma gas pressure. The response parameter was the material removal rate. Air was used as the main cutting gas. The tested material was quenched steel of $12 \mathrm{~mm}$ thick. The effective parameter was the cutting speed, followed by gas pressure, current and the least was the standoff distance.

As seen the main parameters affecting the quality of the produced surface are the cutting speed, the plasma gas pressure and the cutting height (arc gap, standoff distance), so this paper will focus on studying the effect of the three parameters on the quality of cutting hard materials using plasma arc cutting.

\section{Experimental Work}

The plasma arc cutting machine, figure 1, used in the experiment have speeds varying form $100 \mathrm{~mm} / \mathrm{min}$ to 800 $\mathrm{mm} / \mathrm{min}$, pressure ranges from 1 Bar to 8 Bars and a current 
range of $30 \mathrm{~A}$ to $160 \mathrm{~A}$. A nozzle of $1.1 \mathrm{~mm}$ Diameter was

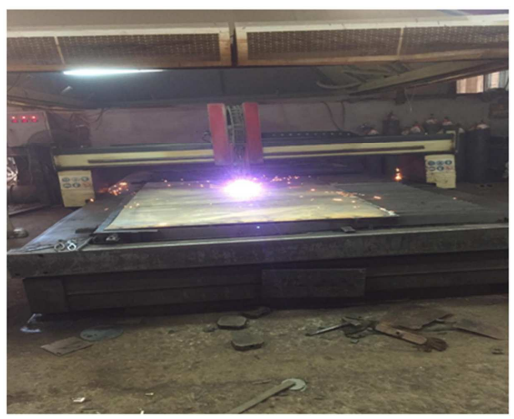

Figure 1. Plasma arc cutting machine with its control panel. used during the whole experimentation.
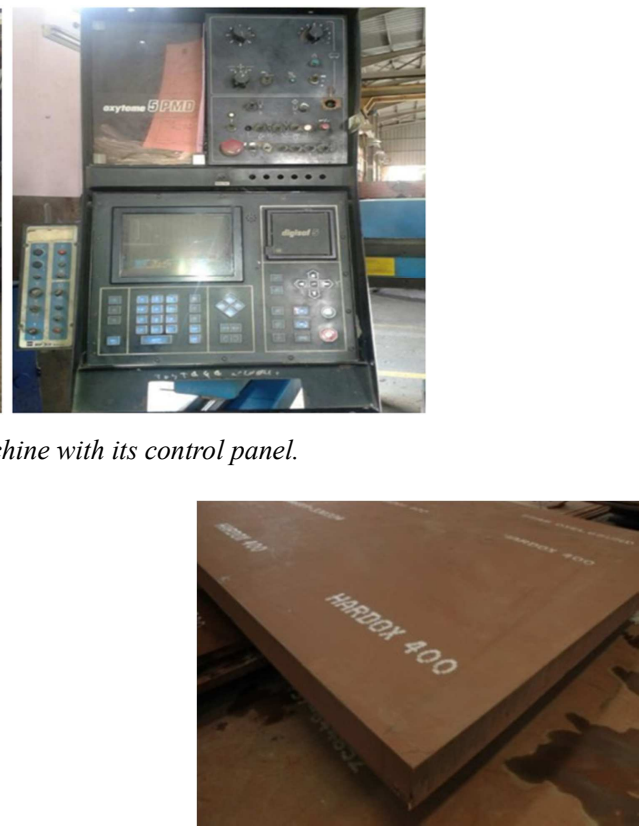

Figure 3. Hardox 400 plates.

The arc gap was adjusted by means of using block gauges of 1, 2, 3, 4 and $5 \mathrm{~mm}$. The test pieces are made of Hardox 400 , of $10 \mathrm{~cm} \times 25 \mathrm{~cm}$, figure 3, Its chemical composition as given table 1 and the average mechanical properties as given in table 2 . The test is to cut $5 \mathrm{~mm}$ cut in the middle of each specimen.

Table 1. Chemical composition of Hadox 400.

\begin{tabular}{lllllllllll}
\hline Element & S & Si & Mo & Mn & C & Ni & B & P & Cr & Fe \\
\hline Wt. $\%$ & 0.010 & 0.70 & 0.60 & 1.46 & 0.32 & 1.50 & 0.04 & 0.025 & 2.50 & Balance \\
\hline
\end{tabular}

Table 2. Mechanical properties of Hardox 400 (STD Dev.).

\begin{tabular}{lllll}
\hline Tensile Strength (MPa) & Yield Strength (MPa) & Impact Energy (J) & Hardness (HV) & Elongation (\%) \\
\hline $1155(5)$ & $878(4)$ & $142(2)$ & $420(1)$ & $16.8(1.5)$ \\
\hline
\end{tabular}

The designed factors are three namely, cutting speed ( $\mathrm{mm} / \mathrm{min}$ ), Gas pressure (bars) and arc gap (standoff distance). The number of levels is five. The designed tests are given in table 3 .

Table 3. Experimental runs (tests).

\begin{tabular}{llll}
\hline Test \# & Cutting speed $(\mathbf{m m} / \mathbf{m i n})$ & Cutting height $\mathbf{( m m})$ & Gas pressure (Bar) \\
\hline 1 & 300 & 3 & 5 \\
2 & 400 & 3 & 5 \\
3 & 500 & 3 & 5 \\
4 & 600 & 3 & 5 \\
5 & 700 & 3 & 5 \\
6 & 700 & 1 & 5 \\
7 & 700 & 2 & 5 \\
8 & 700 & 3 & 5 \\
9 & 700 & 4 & 5 \\
10 & 700 & 5 & 5 \\
11 & 700 & 3 & 4 \\
12 & 700 & 3 & 4.5 \\
13 & 700 & 3 & 5 \\
14 & 700 & 3 & 5.5 \\
15 & 700 & 3 & 6 \\
\hline
\end{tabular}




\section{Results and Discussion}

The results, which are based on the 15 runs listed in table 3 , are fed to Minitab 17 software and based on Taguchi method the results were analyzed and presented in the following sections.

\subsection{Effect of Cutting Speed on Surface Roughness}

The cutting speed has a significant effect on surface roughness. Such results matches those noticed in the literature with the acceptable differences since the input parameters are not unified for all the references. In general the cutting speed proved to be, always, the most affecting input parameters between the considered parameters. This is expected because of the heat developed during cutting as the speed increases. The results are shown in figure 4. They are inversely proportion i.e as the cutting speed increases the surface

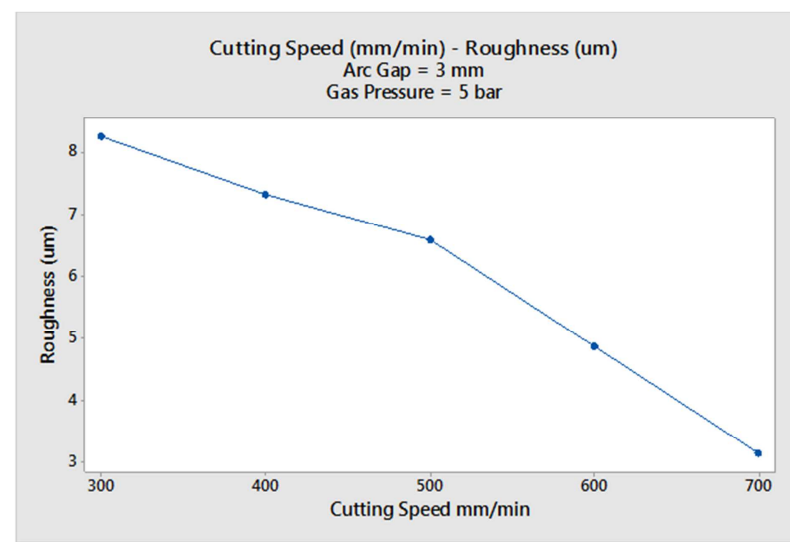

roughness decreases with increasing gradient. Visual observation records that as the cutting speed changes toward $700 \mathrm{~mm} / \mathrm{min}$, the plasma gas gave a clean cut. This may be due to the kinetic energy induced from the high cutting speed which provides a smoother surface relatively with no irregularities in the surface. At low cutting speed the plasma gas after cutting the material, remains at the cut zone for extra fraction of time melting more than required. This is followed by adhesion and poor surface roughness.

Binomial regression equation representing the effect of cutting speed $(\mathrm{S})$ on roughness is obtained:

$$
\mathrm{R}_{\mathrm{a}}=8.1327+0.0057 \mathrm{~S}-2 \times 10^{-5} \mathrm{~S}^{2}
$$

The mean value of the results is $6.037 \mu \mathrm{m}$. The standard deviation is 2.032

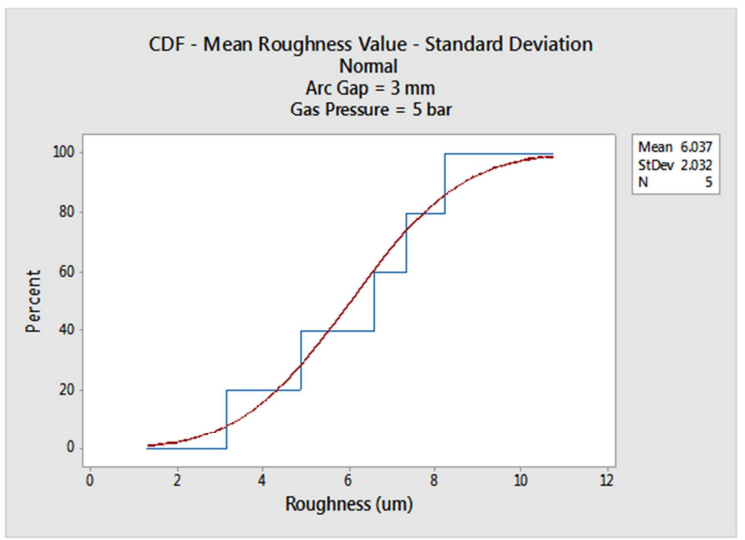

Figure 4. Effect of cutting speed on Roughness.

\subsection{Effect of Pressure on Surface Roughness}

The results are given in figure 5. It is obvious that plasma gas pressure also has an effect on surface roughness, As the plasma gas pressure increases the surface roughness decreases. Variation of roughness for gas pressure up to about 5 bar seems to be little as compared with that of high pressure. This may be attributed with the fact that at high plasma gas pressure the plasma gas blows away the molten metal form the cut zone thus re-adhesion and built-up metals and hence resulting for

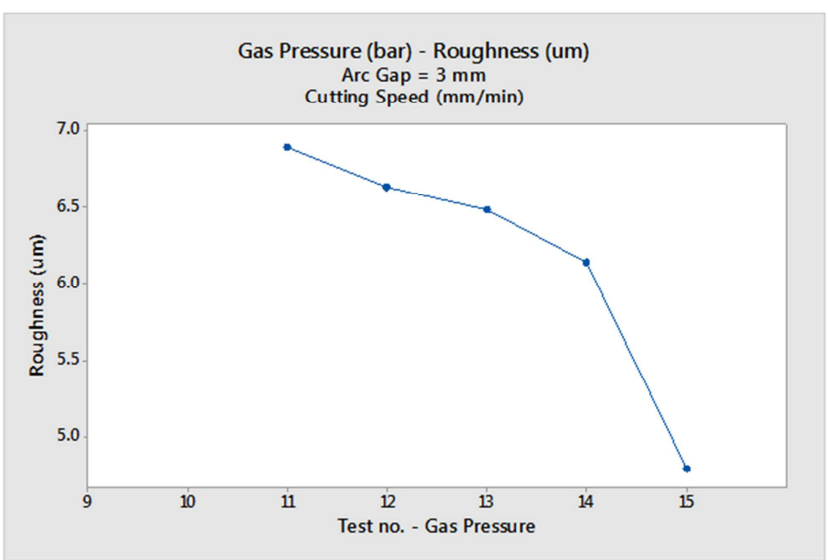

good surface roughness. At low plasma gas pressure, the gas flow is just sufficient to cut but not to entirely blow away the metal form the surface of the cut.

The regression equation of the gas pressure (p) on roughness (based on binomial function) is:

$$
R_{a}=-5.6766+5.8193 p-0.6757 p^{2}
$$

The mean value of the results is $6.189 \mu \mathrm{m}$. The standard deviation is 0.8258

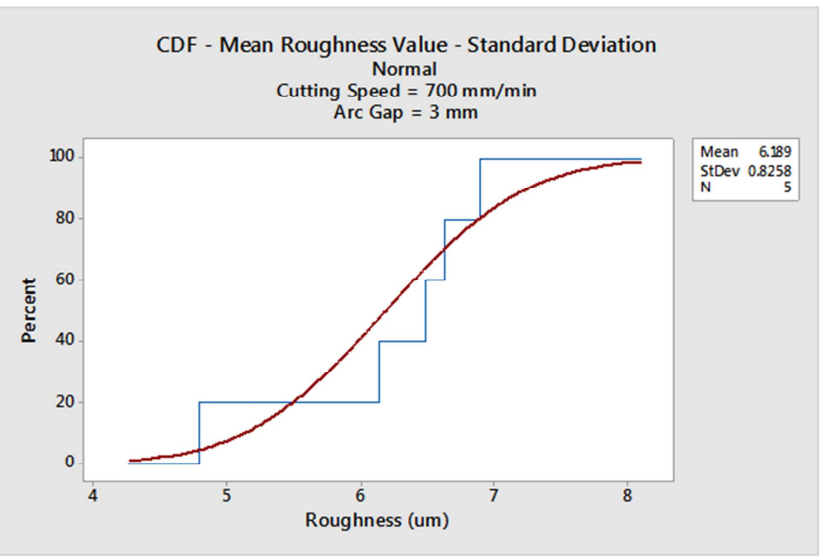

Figure 5. Effect of Plasma gas pressure on Roughness. 


\subsection{Effect of Arc Gap on Surface Roughness}

The arc gap (standoff distance) minor effect on surface roughness. The results are shown in figure 6 . Surface roughness is directly affected by the arc gap. The increase in roughness is considered for the slower melting which may result in top edge curvature and hence, less accuracy at the edge.

The regression equation for the effect of arc gap (d) on the
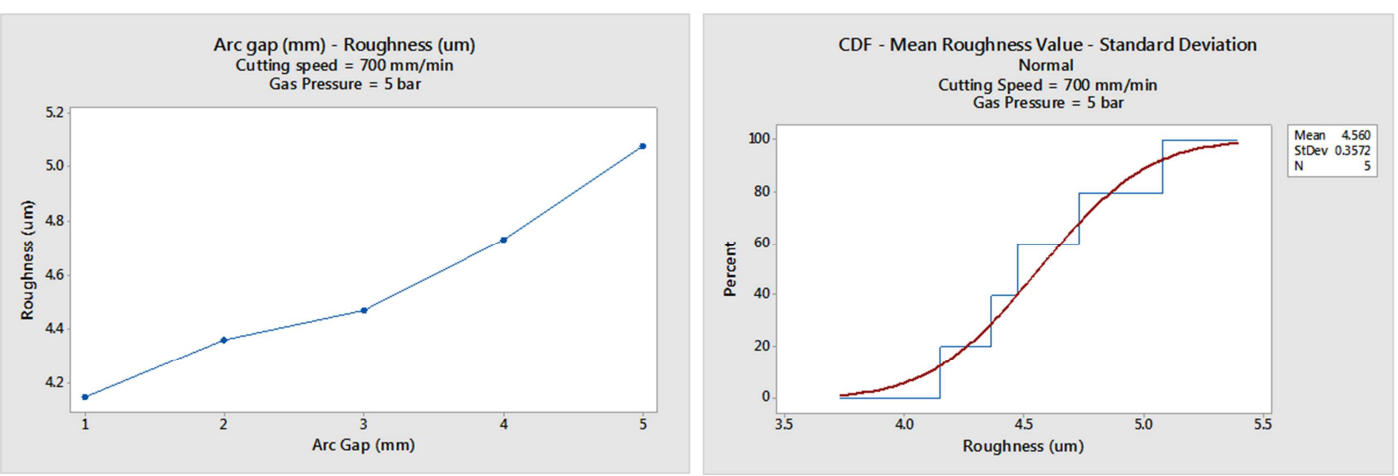

Figure 6. Effect of Arc gap on Roughness.

\section{Conclusion}

The average surface roughness calculated for the three factors was around to range from 5 to $5.5 \mu \mathrm{m}$, which may be considered equivalent to the rough machining operation (milling). However, the time consumed with cutting using the plasma arc cutting is extremely small.

The cutting speed showed greater effect on the surface roughness and it should be increased as great as possible. It was followed by the gas pressure which should be maintained as high as possible. The inter-relation between them is represented in the Binomial regression equation

$$
\mathrm{R}_{\mathrm{a}}=8.1327+0.0057 \mathrm{~S}-2 \times 10^{-5} \mathrm{~S}^{2}
$$

The mean value of the results is $6.037 \mu \mathrm{m}$. The standard deviation is 2.032

The lowest surface roughness value is $3.152 \mu \mathrm{m}$ was obtained at high cutting speeds $700 \mathrm{~mm} / \mathrm{min}$ with moderate plasma gas pressure $300 \mathrm{kPa}$, arc gap $5 \mathrm{~mm}$ and relatively high current $120 \mathrm{~A}$.

Changing the arc gap appears to have little effect on surface roughness within the range studied.

\section{References}

[1] Milan Kumar Das, Kaushik Kumar, Tapan Kr Barman, Prasanta Sahu, "optimization of process parameters in plasma arc cutting of EN 31 steel based on MRR and multiple roughness characteristics using grey relational analysis" Procedia material science, vol. 5, pp. 1550-1559, 2014.

[2] K. Salonitis, S. Vatousianos, "Experimental Investigation of the Plasma Arc Cutting Process", Procedia CIRP, vol. 3 pp. 287 292, (2012)

[3] Parthkumar Patel, Bhavdeep Nakum, Kumar Abhishek, V. roughness (based on binomial function) is:

$$
\mathrm{R}_{\mathrm{a}}=4.0976+0.0473 \mathrm{~d}+0.0291 \mathrm{~d}^{2}
$$

The mean value of the results is $4.5602 \mu \mathrm{m}$. The standard deviation is 0.3572
Rakesh Kumar, Anshuman Kumar "Optimization of Surface Roughness in Plasma Arc Cutting of AISID2 Steel Using TLBO" Materials Today, Volume 5, Issue 9, Part 3, (2018).

[4] Yahya Hisman Celik, "investigating the effect of cutting parameters on material cut in CNC plasma" materials and manufacturing processes, vol. 28, pp. 1053-1060, 2013.

[5] Chirag K. Kolambe and Sambhaji V. Sagare, "Plasma arc Cutting Parameters using TAGUCHI Method", International Journal for Scientific Research \& Development, Vol 8, Issue 9, pp 2321-0613, 2020.

[6] Sugar S. and Dr. K. H. Inamdar, "Factors sffecting quality of plasma cutting process: A review", International Journal pf Advanced Technology in Engineering and Science, Vol no. 4, Issue N0. 12, December 2016.

[7] Deepak Kumar Naik \& Kalipada Maity, "Experimental analysis of the effect of gas flow rate and nature on plasma arc cutting of hardox-400", Welding in the World (2020) 64: 345352, https://doi.org/10.1007/s40194-019-00836-8.

[8] Deepak K Kumar Naik and Kalipada Maity, "Application of desirability function based response surface methodology (DRSM) for investigating the plasma arc cutting process of sailhard steel", World Journal of Engineering, 15/4 (2018) 505512, (C) Emerald Publishing Limited [ISSN 1708-5284], [DOI 10.1108/WJE-06-2017-0125].

[9] Naik DK, Maity K (2019) Temperature analysis by moving heat source during plasma arc cutting process: an analytical approach. World Journal of Engineering 16 (4): 569-572.

[10] Naik DK, Maity K (2018) Optimization of dimensional accuracy in plasma arc cutting process employing parametric modelling approach. IOP Conference Series: Materials Science and Engineering 338: 1-6.

[11] Naik DK, Maity K (2018) An optimization and experimental analysis of plasma arc cutting of Hardox-400 using Taguchi based desirability analysis. Materials Today: Proceedings 5 (5): 13157-13165. 
[12] Omar Monir Koura, Sarah Atef Afifi, Mervat Tawfik, Samah Samir Mohamme , "Effects of Plasma Arc cutting Parameters on the Response of cutting hard material", IOSR Journal of Mechanical and Civil Engineering (IOSR-JMCE) e-ISSN: 2278-1684, p-ISSN: 2320-334X, Volume 18, Issue 3 Ser. IV (May - June 2021), PP 31-36.

[13] Sovan Bhowmick, Jisnu Basu, Gautam Majumdar, Asish Bandyyopadhyay, "Experimental studt of plasma arc cutting of AISI 304 stainless steel”, materialstoday, proceedings, Vol. 5, Issue 2, Part 1, 2018, pp 4541-4550.

[14] Pothur Hema and Ramprasad Ganesan, "Experimental investigation on SS 304 alloy using plasma arc machining", SN Applied Science (2020) 2: 624| http://doi.org/10.1007/s42452-020-2350-y
[15] Pulkit Kumar Agrawal, Pulkit Kumar Agrawal, Dilip Kumar Bagal, Ajit Kumar Pattanaik, Abhishek Barua, Siddharth Jeet, Biswajit Parida, Surya Narayan Panda, "Experimental Investigation of Cutting Parameters in Plasma Arc Cutting Using Advanced Optimization Approach: A Comprehensive Review", International Journal of Applied Engineering Research ISSN 0973-4562 Volume 14, Number 13, 2019 (Special Issue) (C) Research India Publications. http://www.ripublication.com

[16] Sahil Sharma, Mukesh Gupta, Raj Kumar, N. S. Bindra, "Experimental Analysis and Optimization of Process Parameters in Plasma Arc Cutting Machine of EN-45A Material Using Taguchi and ANOVA Method", World Academy of Science, Engineering and Technology International Journal of Mechanical and Industrial Engineering Vol: 11, No: 7, 2017. 